\title{
Personality Correlates of Gaming and Pornography Use
}

\author{
Madison Calvert, Madison Linden, Katie Kyser, Kassi Zeinert, and Michelle Singer \\ Foust
}

Lorain County Community College $(\mathrm{OH})$

Suggested bibliographic reference

Calvert, M., Linden, M., Kyser, K., Zeinert, K., \& Foust, M. S. (2021). Personality correlates of gaming and pornography use. Psi Beta Journal of Research, 1(1), 34-40.

https://doi.org/10.54581/JPWV2620

\begin{abstract}
Internet use has become a prominent part of everyday life, with some individuals using the internet as a tool and others for entertainment. Excessive involvement with the internet, however, can lead to disruptions in daily living and may affect general functioning (Crosby \& Twohig, 2016; Kuss et al., 2017). The purpose of this study was to investigate whether individuals with certain personality traits are more likely to engage in excessive internet use behaviors. Using a correlational design and an online research questionnaire, gaming and pornography use were examined in relation to anxiety, impulsivity, narcissism, sexual narcissism, and Type D personality using a correlation and regression model. Consistent with previous research, the current study found that gaming use had a significant positive correlation with anxiety and impulsivity. Additionally, significant positive relationships were found between pornography use and impulsivity, narcissism, and sexual narcissism. A new contribution to the literature is the finding that Type D personality was associated with higher gaming use. Despite falling under the umbrella of problematic internet use behaviors, gaming and pornography use appear to be quite distinct; only impulsivity was correlated with both gaming and pornography. Moreover, regression analysis found that impulsivity significantly predicted gaming use while sexual narcissism significantly predicted pornography use. Further research is needed to determine the extent to which gaming and pornography use are coping mechanisms for people with certain personality characteristics. Nonetheless, the current study suggests that understanding personality variables associated with gaming and pornography use may be helpful in mitigating the risk of developing problematic internet use behaviors.
\end{abstract}

Keyword: gaming, pornography, problematic internet use, personality characteristics

As internet use becomes an increasingly prominent component of daily life, problematic behaviors pertaining to a wide range of activities performed using the internet are being seen. The present study focused on two types of online activities: internet gaming and internet pornography use. Excessive involvement with video games may impose on other activities of daily life and potentially lead to the development of Internet Gaming Disorder (IGD; Kuss et al., 2017). Simi- larly, excessive use of internet pornography may interfere with general functioning, result in negative cognitions, and develop into problematic pornography use (PPU; Crosby \& Twohig, 2016). The current study focused on the extent of internet gaming and pornography use in relation to various personality characteristics: trait anxiety, impulsivity, narcissism, sexual narcissism, and Type D personality. In general, anxiety has been found to be a significant correlate of problematic internet 
use behaviors (Lee \& Stapinski, 2012). Specifically, several studies found that anxiety is positively associated with IGD (Adams et al., 2019; Bargeron \& Hormes, 2017; Bonnaire \& Baptista, 2019; Marino et al., 2020; Wang et al., 2017) as well as PPU (Niazof et al., 2019; Shirk et al., 2021). Trait anxiety is defined as a relatively stable state of proneness to experiencing anxiety (Julian, 2011). As trait anxiety increases, gaming and pornography use scores also increase. Similarly, impulsivity - the tendency to display behavior with little or no forethought, reflection, or consideration of the consequences-has previously been found to play a role in the development and maintenance of some problematic internet use behaviors, both with IGD (Hu et al., 2017; Kuss \& Griffiths, 2012) and PPU (Antons \& Brand, 2018).

Narcissism is a relatively stable pattern of grandiosity in which individuals are egotistical, love being the center of attention, and lack empathy for others (Weber, 2016). It has been found that increased pornography use is positively correlated to an individual's level of narcissism (Kasper et al., 2015); however, the relationship between narcissism and gaming appears to be more complex. Previous research conducted through a clinical lens found narcissism to be positively correlated with online gaming addiction (Stopfer et al., 2015), while other research has found more of an indirect relationship between problematic online gaming and narcissism (Kircaburun et al., 2018). Narcissism may also act as a mediator or moderator for problematic online gaming. Despite this complexity, the general consensus is that as scores for narcissism increase, problematic gaming scores increase as well (Stopfer et al., 2015). Distinct from narcissism, sexual narcissism refers to the relatively stable pattern of dysfunctional forms of sexual interaction that are characterized by the inability to express intimacy and are rooted in low self-esteem as well as insecurity (Apt \& Hurlbert, 1995). While it has been found that individuals who use pornography have higher levels of sexual narcissism (Kasper et al., 2015), not much is currently known about the relationship between sexual narcissism and internet gaming.

Holdoš (2017) defined Type D (distressed) personality as the tendency to experience more negative affectivity (i.e., negative emotions) along with social inhibition (i.e., lack of emotion and behavior expression in social situations). While there is a lack of scientific literature specifically examining the relationship between Type D personality and pornography use, Holdoš (2017) states it is plausible that Type D personality could be a predictor of problematic internet gaming, because when someone shows high signs of social inhibition, they are more likely to engage in hobbies that are independent. Individuals who are Type D scored higher on internet addiction than individuals who are not Type $\mathrm{D}$, meaning this personality characteristic could be a risk factor for internet addiction (Holdoš, 2017). Similarly, Kim et al. (2016) found that an internet gaming addiction group had more type D participants than a noninternet gaming addiction group.

Relationships have been established between many personality traits and problematic internet use behaviors such as gaming or pornography, but little to no research has been done on personality traits correlated with both behaviors. Acknowledging both the many similarities and gaps found in the literature review, the present study explored the personality correlates associated with both internet gaming and pornography use. It was hypothesized that anxiety, impulsivity, narcissism, sexual narcissism, and Type D personality characteristics are correlates of both internet gaming use and pornography use. Additionally, it was hypothesized that these personality traits would predict the extent of gaming and pornography use.

\section{Method}

\section{Participants}

Participants were 185 individuals recruited voluntarily through online platforms such as social media and college class forums who ranged in 
age from 18 to 65 with a mean age of 23.51 years old $(S D=7.54)$. Most of the participants were female $(60 \%)$ and had at least some college education $(74.60 \%)$. More participants were in a relationship or married $(48.60 \%)$ than those who were single or not currently in a relationship (40.5\%). The sample was $76.20 \%$ European American, 8.10\% Hispanic/Latino, $\quad 5.90 \% \quad$ Biracial/Multiracial, and 4.90\% African American.

\section{Procedure}

After gaining approval from the institutional review board (IRB \#1949), an electronic link to a self-report research questionnaire was distributed through the online platforms Facebook and Reddit to recruit voluntary participants. Some participants were recruited through psychology courses and were offered extra credit for participation. Prior to participating in the study, participants were informed about the method of maintaining participant anonymity and data confidentiality as well as the risks and benefits of participation through reading and signing an informed consent. It was explained to participants that the purpose of the study was to examine personality in relation to video game and pornography usage. After completing the questionnaire, participants were provided with the Substance Abuse and Mental Health Services Administration's (SAMHSA) national helpline (U.S. Department of Health and Human Services, 2021) and an addiction resource website (Substance Abuse Resources, n.d.) to answer questions they may have had about their video game or pornography use.

\section{Measures}

Gaming use was evaluated using the 21-item Game Addiction Scale (Lemmens et al., 2009) which measures potentially problematic gaming behaviors. The 18-item Problematic Pornography Consumption Scale (PPCS; Böthe et al., 2018) was used to assess pornography use and the extent to which using pornography is problematic for an individual. The Trait Anxiety Scale, a 20-item subscale of the State-Trait Anxiety Inventory
(STAI; Spielberger et al., 1970), was used for participants to describe their anxious tendencies. Impulsivity was measured using the 30-item Barratt Impulsiveness Scale Version 11 (BIS-11; Patton et al., 1995). The Narcissistic Personality Inventory (NPI-16) was used to assess an individual's grandiose sense of self, level of entitlement, preoccupation with success, and demands for admiration (Ames et al., 2006). Sexual narcissism was measured using the 20-item Sexual Narcissism Scale (SNS; Widman \& McNulty, 2010) to assess narcissistic aspects of an individual's sexual experiences. For each of these measures, scale scores were calculated by averaging the items, and higher scores reflected more of the characteristic being assessed. The Type D Scale-14 (DS14; Denollet, 2005), using seven items to assess negative affectivity and seven items to assess social inhibition, was used to determine the extent to which a person has a Type D personality. A person is classified as having a Type D personality if they score high on both the negative affectivity and social inhibition scales. Research has demonstrated strong psychometric properties of all measures.

\section{Results}

An average of 7.71 hours of weekly gaming $(S D=10.58)$ was reported, ranging from 0 to 50 hours per week. The average age of first gaming use was 7.56 years old $(S D=4.72)$. An average of 1.28 hours of weekly pornography use $(S D=$ 2.21) was reported, ranging from 0 to 20 hours weekly. The average age of first pornography use was 11.76 years old $(S D=6.38)$.

Descriptive statistics for all variables in the current study can be found in Table 1 . The coefficient alpha reliability estimates in our sample met the acceptable level of .70 or higher for all variables. Recall that a person is considered to have a Type D personality when they have a specific combination of high negative affectivity coupled with high social inhibition. In our sample, $57.2 \%$ of participants identified as Type D. 
Table 1

Descriptive Statistics and Coefficient Alphas for all Study Variables

\begin{tabular}{lcccccc}
\hline \multicolumn{1}{c}{ Variable } & Mean & SD & Range & Minimum & Maximum & Alpha \\
\hline Gaming Use & 1.86 & .73 & $1.00-5.00$ & 1.00 & 4.43 & .95 \\
Pornography Use & 1.47 & .75 & $1.00-7.00$ & 1.00 & 7.00 & .94 \\
Anxiety & 2.46 & .54 & $1.00-4.00$ & 1.20 & 3.60 & .92 \\
Impulsivity & 2.13 & .35 & $1.00-4.00$ & 1.13 & 3.20 & .82 \\
Narcissism & 2.60 & .68 & $1.00-5.00$ & 1.00 & 4.50 & .89 \\
Sexual Narcissism & 2.05 & .54 & $1.00-5.00$ & 1.00 & 4.30 & .85 \\
Social Inhibition & 1.99 & .97 & $0.00-4.00$ & 0.00 & 4.00 & .85 \\
Negative Affect & 2.06 & 1.05 & $0.00-4.00$ & 0.00 & 4.00 & .90 \\
\hline
\end{tabular}

Note. Gaming use was measured using the Game Addiction Scale (Lemmens et al., 2009), pornography use was measured using the Problematic Pornography Consumption Scale (PPCS; Böthe et al., 2018), anxiety was measured using the Trait Anxiety Subscale of the State-Trait Anxiety Inventory (STAI; Spielberger et al., 1970), impulsivity was measured using the Barratt Impulsiveness Scale Version 11 (BIS-11; Patton et al., 1995), narcissism was measured using the Narcissistic Personality Inventory (NPI-16; Ames et al., 2006), sexual narcissism was measured using the Sexual Narcissism Scale (SNS; Widman \& McNulty, 2010), and Type D personality (social inhibition and negative affect) was measured using the Type D Scale-14 (DS14; Denollet, 2005).

Our first hypothesis assessed anxiety, impulsivity, narcissism, sexual narcissism, and Type D as personality correlates of gaming and pornography use. Results found that gaming use had significant positive correlations with anxiety, $r(183)=$ $.16, p=.03$, impulsivity, $r(183)=.29, p<.001$, and Type D personality, $r(183)=.18, p=.02$, demonstrating small to moderate effect sizes (Cohen, 1992). There were no significant relationships found between gaming use and narcissism or sexual narcissism. We found significant positive relationships between pornography use and impulsivity, $r(183)=.22, p=.003$, narcissism, $r(183)=.28, p<.001$, and sexual narcissism, $r(183)=.48, p<.001$, demonstrating moderate to large effect sizes (Cohen, 1992). There were no significant relationships found between pornography use and anxiety or Type D personality.

Multiple regression analysis was used to test our second hypothesis, that personality traits would significantly predict gaming and pornography use. The results of the regression indicated only impulsivity significantly predicted gaming use, $\beta=.59, t(183)=3.68, p<.001$. Impulsivity explained a significant proportion of the variance in gaming use scores, $R^{2}=.13, F(6,178)=4.29, p$ $<.001$. Type $\mathrm{D}$ personality emerged as a marginally significant predictor of gaming use, $\beta=.22$, $t(183)=1.81, p=.07$. Only sexual narcissism emerged as a significant predictor of pornography use, $\beta=.57, t(183)=5.54, p<.001$. Sexual narcissism explained a significant proportion of the variance in pornography use scores, $R^{2}=.25, F(6$, $178)=10.01, p<.001$.

\section{Discussion}

The goal of the present study was to examine personality correlates of gaming and pornography use to discern similarities and differences in these two problematic internet use behaviors. In partial 
support of hypothesis one and consistent with previous research, we found anxiety (e.g., Marino et al., 2020) and impulsivity (Hu et al., 2017; Kuss \& Griffiths, 2012) to have a significant positive correlation with gaming use. It may be that as individuals become more anxious and impulsive, their gaming behaviors become more prevalent. We did not confirm a significant relationship between narcissism and increased gaming use, contrary to previous research (Stopfer et al., 2015). A new contribution to the literature is our finding that Type D personality - those individuals that are high in negative affectivity coupled with being high in social inhibition-was also associated with higher gaming use. Interestingly, it may be that anxiety increases when people with Type D are in social situations because for them socializing may not come easily. The internet allows individuals to feel like part of society without the strain of communicating in person, and this can be especially helpful for individuals who are higher in social inhibition. One avenue for future research is to ascertain if Type D individuals are engaging in team gaming to gain more comfortable social interaction. In partial support of hypothesis two, we found that impulsivity and Type D personality (marginally) predicted gaming use, which leads us to consider the combination of impulsivity and Type D personality leading to problematic gaming behavior.

Regarding pornography use in hypothesis one, we confirmed previous research in that those with more impulsivity, narcissism, and sexual narcissism were more likely to engage in pornography consumption (Antons \& Brand, 2018; Kasper et al., 2015). Interestingly, we did not find a direct relationship between anxiety and an individual's pornography use, contrary to previous research (Niazof et al., 2019; Shirk et al., 2021). It appears that engaging in more pornography did not correspond with more anxiety in our sample. Furthermore, in partial support of hypothesis two, sexual narcissism was the only personality characteristic to predict pornography use. Individuals who are more self-absorbed in their sexual encounters and not as concerned about their partner's enjoyment seem to watch more pornography, perhaps making it all about their own pleasure.

Results suggest that despite falling under the umbrella of problematic internet use behaviors, gaming and pornography use appear to be quite distinct; we found only impulsivity to be correlated to both gaming and pornography. Still, we wonder about the use of these behaviors as coping mechanisms for people with certain personality characteristics, or combinations of personality characteristics. Individuals with more anxiety, impulsivity, or negative affect coupled with social inhibition may be more likely to cope by gaming. Additionally, individuals with more impulsivity, narcissism, or sexual narcissism might be more likely to use pornography as a coping strategy. Considering these findings, we conclude that knowing the personality correlates of internet gaming and pornography use may be valuable in mitigating the risk of developing problematic or addictive internet use behaviors. Future investigations should examine to what extent these problematic behaviors are coping strategies.

As with all research, there are certain limitations of our study. The data in our study were responses to a self-reported questionnaire using standardized, reliable, and valid measures. However, there is a possibility that self-report data can lead to common method bias. Gaining access to data that is not self-reported in future research studies can help to avoid threats to the internal validity of a study. Also, regarding limitations within our sample, most $(76.20 \%)$ identified as European American and 60\% identified as female, which limits generalizability of the results. Future research would benefit from having a more diverse sample. Finally, our participants reported a relatively low number of average hours of weekly gaming and weekly pornography use. Caution should be used when trying to determine how the personality characteristics examined in this study 
relate to excessive gaming and pornography use. Perhaps future research can intentionally sample individuals with greater internet use to allow comparisons to be made between moderate and excessive gaming and pornography use.

\section{References}

Adams, B. L. M., Stavropoulos, V., Burleigh, T. L., Liew, L. W., Beard, C. L., \& Griffiths, M. D. (2019). Internet gaming disorder behaviors in emergent adulthood: A pilot study examining the interplay between anxiety and family cohesion. International Journal of Mental Health and Addiction, 17, 828-844. https://doi.org/10.1007/s11469-018-9873-0

Ames, D. R., Rose, P., \& Anderson, C. P. (2006). The NPI-16 as a short measure of narcissism. Journal of Research in Personality, 40(4), 440-450. https://doi.org/10.1016/j.jrp.2005.03.002

Antons, S., \& Brand, M. (2018). Trait and state impulsivity in males with tendency towards Internet pornography-use disorder. Addictive Behaviors, 79, 171-177. https://doi.org/10.1016/j.addbeh.2017.12.029

Apt, C. \& Hurlbert, D. F. (1995). Sexual narcissism: Addiction or anachronism? The Family Journal, 3(2), 103-107. https://doi.org/10.1177/1066480795032003

Bargeron, A., \& Hormes, J. (2017). Psychosocial correlates of internet gaming disorder: Psychopathology, life satisfaction, and impulsivity. Computers in Human Behavior, 68, 388-394.

https://doi.org/10.1016/j.chb.2016.11.029.

Bonnaire, C., \& Baptista, D. (2019). Internet gaming disorder in male and female young adults: The role of alexithymia, depression, anxiety and gaming type. Psychiatry Research, 272, 521-530. https://doi.org/10.1016/j.psychres.2018.12.158

Böthe, B., Toth-Kiraly, I., Zsila, A., Demetrovics, Z., Griffiths, M. D., \& Orosz, G. (2018). The development of the Problematic Pornography Consumption Scale (PPSC). APA PsycTests. https://doi.org/10.1037/t66347-000

Cohen, J. (1992). A power primer. Psychological Bulletin, 112, 155-159. https://doi:10.1037/0033$\underline{2909.112 .1 .155}$

Crosby, J. M., \& Twohig, M. P. (2016). Acceptance and commitment therapy for problematic internet pornography use: A randomized trial. Behavior Therapy, 47(3), 355-366. https://doi.org/10.1016/j.beth.2016.02.001

Denollet, J. (2005). DS14: Standard assessment of negative affectivity, social inhibition, and type D personality. Psychosomatic Medicine, 67(1), 89-97. https://doi.org/10.1097/01.psy.0000149256.81953 .49

Holdoš, J. (2017). Type D Personality in the prediction of internet addiction in the young adult population of Slovak internet users. Current Psychology, 36(4), 861-868. https://doi.org/10.1007/s12144016-9475-6

Hu, J., Zhen, S., Yu, C., Zhang, Q., \& Zhang, W. (2017). Sensation seeking and online gaming addiction in adolescents: A moderated mediation model of positive affective associations and impulsivity. Frontiers in Psychology, 8, 699. https://doi.org/10.3389/fpsyg.2017.00699

Julian L. J. (2011). Measures of anxiety: State-Trait Anxiety Inventory (STAI), Beck Anxiety Inventory (BAI), and Hospital Anxiety and Depression Scale-Anxiety (HADS-A). Arthritis Care \& Research, 63(11), S467-S472. https://doi.org/10.1002/acr.20561

Kasper, T. E., Short, M. B., \& Clinton M. A. (2015). Narcissism and internet pornography use. Journal of Sex and Marital Therapy, 41(5), 481-486. https://doi.org/10.1080/0092623X.2014.931313

Kim, N., Hughes, T. L., Park, C. G., Quinn, L., \& Kong, I. D. (2016). Altered autonomic functions and distressed personality traits in male adolescents with internet gaming addiction. Cyberpsychology, Behavior, and Social Networking, 19(11), 667-673. https://doi.org/10.1089/cyber.2016.0282

Kircaburun, K., Jonason, P. K., \& Griffiths M. D. (2018). The Dark Tetrad traits and problematic online gaming: The mediating role of online gaming motives and moderating role of game types. Personality and Individual Differences, 135, 298303. https://doi.org/10.1016/j.paid.2018.07.038

Kuss, D. J., \& Griffiths, M. D. (2012). Internet and gaming addiction: A systematic literature review of neuroimaging studies. Brain Sciences, 2(3), 347-374. https://doi.org/10.3390/brainsci2030347

Kuss, D. J., Griffiths, M. D., \& Pontes, H. M. (2017). DSM-5 diagnosis of Internet Gaming Disorder: Some ways forward in overcoming issues and 
concerns in the gaming studies field. Journal of Behavioral Addictions, 6(2), 133-141.

https://doi.org/10.1556/2006.6.2017.032

Lee, B. W., \& Stapinski, L. A. (2012). Seeking safety on the internet: Relationship between social anxiety and problematic internet use. Journal of Anxiety Disorders, 26(1), 197-205.

https://doi.org/10.1016/j.janxdis.2011.11.001

Lemmens, J. S., Valkenburg, P. N., \& Peter, J. (2009). Development and validation of a Game Addiction Scale for adolescents, Media Psychology, 12(1), 77-95.

https://doi.org/10.1080/15213260802669458

Marino, C., Canale, N., Vieno, A., Caselli, G., Scacchi, L., \& Spada, M. M. (2020). Social anxiety and Internet gaming disorder: The role of motives and metacognitions. Journal of Behavioral Addictions, 9(3), 617-628. https://doi.org/10.1556/2006.2020.00044

Niazof, D., Weizman, A., \& Weinstein, A. (2019). The contribution of ADHD and attachment difficulties to online pornography use among students. Comprehensive Psychiatry, 93, 56-60. https://doi.org/10.1016/j.comppsych.2019.07.002

Patton, J. H., Stanford, M. S., \& Barratt, E. S. (1995). Factor structure of the Barratt Impulsiveness Scale. Journal of Clinical Psychology, 51(6), 768774. https://doi.org/10.1002/10974679(199511)51:6

Shirk, S. D., Saxena, A., Park, D., \& Kraus, S. W. (2021). Predicting problematic pornography use among male returning US veterans. Addictive Behaviors, 112, 1-6. https://doi.org/10.1016/j.addbeh.2020.106647

Spielberger, C. D., Gorsuch, R. L., \& Luchene, R. E. (1970). The State Trait Anxiety Inventory. Consulting Psychologists Press.

Stopfer, J. M., Braun, B., Muller, K. W., \& Egloff, B. (2015). Narcissus plays video games. Personality and Individual Differences, 87, 212-218. https://doi.org/10.1016/j.paid.2015.08.011

Substance abuse resources: All the help you need to beat addiction. (n.d.). Addiction Resource. Retrieved August 6, 2021, from https://addictionresource.com/

U.S. Department of Health and Human Services, Substance Abuse and Mental Health Services Administration. (2021, May 25). SAMHSA national helpline. https://www.samhsa.gov/findhelp/national-helpline.

Wang, C. Y., Wu, Y. C., Su, C. H., Lin, P. C., Ko, C. H., \& Yen, J. Y. (2017). Association between internet gaming disorder and generalized anxiety disorder. Journal of Behavioral Addictions, 6(4), 564-571. https://doi.org/10.1556/2006.6.2017.088

Weber, R. (2016). The real narcissists. Psychology Today. 53-61.

Widman, L, \& McNulty, J. K. (2010). Sexual narcissism and the perpetration of sexual aggression. Archives of Sexual Behavior, 39, 926-939. https://doi.org/10.1007/s10508-008-9461-7 